\title{
A história recente das Ciências da Terra como estratégia de ensino para confrontar representações epistemológicas ingênuas ${ }^{*}$
}

\author{
Leonor Bonan \\ Centro de Formación e Investigación en \\ Enseñanza de las Ciencias, Universidad de \\ Buenos Aires, Ibonan@de.fcen.uba.ar
}

\footnotetext{
*Este artigo deve ser referido como segue:

Bonan L. 2009. A história recente das Ciências da Terra como estratégia de ensino para confrontar representações epistemológicas ingênuas. Terræ Didatica, 5(1):04-09<http:// www.ige.unicamp.br/ terraedidatica/>

1 Trabalho originalmente exposto em espanhol no $14^{\circ}$ Simposio sobre Enseñanza de la Geología, Aveiro, Portugal, 2024/07/2006. Tradução e notas de Pedro Wagner Gonçalves.
}

\begin{abstract}
RECENT EARTH SCIENCE HISTORY AS A TEACHING STRATEGY TO CONFRONT NAIVE VIEWS OF SCIENCE. In this work we try to make visible some epistemological aspects that are usually hidden by teaching. To do that we expose in a schematic way the recent evolution of the research domain associated to mantle convection. The analysis allows to indicate that epistemological aspects should be included in the undergraduate courses of Geology and Geophysics.
\end{abstract}

KEYWORDS Earth Science history, scientific activity, teaching strategy.

RESUMO Este trabalho procura evidenciar aspectos epistemológicos ocultos no ensino. Para tanto, apresenta de forma simplificada a evolução das pesquisas sobre convecção no manto e explora a controvérsia existente entre modelos diferentes. A partir dessa análise, indica-se que aspectos epistemológicos deveriam ser considerados no ensino superior de Geologia e Geofísica.

PALAVRAS-CHAVE História das Ciências da Terra, atividade científica, estratégia de ensino. 


\section{Introdução}

A importância de representações epistemológicas ingênuas pode passar desapercebida quando o ensino de ciências é centrado exclusivamente no enfoque conceitual como ocorre no segmento final dos cursos de formação profissional de geólogos e geofísicos. Especialmente no nível universitário o ensino apóia-se na transmissão do conhecimento científico atualizado, sem permitir que os estudantes tratem das estratégias de construção da ciência. Os alunos, ao mesmo tempo que aprendem, sincrônica e subrepticiamente, constroem representações que, em termos amplos, pouco diferem das chamadas concepções epistemológicas ingênuas (AdúrizBravo et al. 2002).

Este trabalho dá continuidade a estudos anteriores (Bonan 2002; Bonan et al. 2004) nos quais são desenvolvidos os fundamentos teóricos das nossas propostas didáticas. Nos trabalhos expomos como evoluiu a teoria de convecção do manto desde a época de aceitação da teoria de tectônica de placas até hoje. $\mathrm{O}$ foco de tais pesquisas é tratar de problemas epistemológicos associados ao ensino universitário. ${ }^{1 \mathrm{NT}}$

\section{Nossa abordagem: caracterização de uma metodologia}

\subsection{Princípios básicos da atividade científica ${ }^{2 \mathrm{NT}}$}

Investigações da Didática das Ciências mostraram que a educação científica produz representações da ciência muito distantes das concepções epistemológicas atuais. Uma intervenção didática que procure mobilizar essas representações tem como primeira tarefa caracterizar um marco epistemológico para, em seguida, propor um modelo de abordagem que tente confrontá-las. Adotamos a caracterização de atividade científica que reconhece coincidências de várias atitudes epistemológicas, deixando de lado dissidências que se encontrem distantes do projeto de intervenção didática (Gil et al. 2005). Autores como Stephan E. Toulmin, Karl Popper, Thomas Kuhn, Mario Bunge, Larry Laudan e Ronald N. Giere, entre outros, admitem que a ciência se caracteriza pelos seguintes aspectos essenciais:

1. A criação do conhecimento científico não se acha vinculada a uma metodologia universal, ao invés disso, cada domínio de investigação adota formas metodológicas particulares, desprezando certo conjunto de receitas exaustivas e infalíveis.

2. Os dados empíricos não são objetivos, ao contrário, de fato são interpretados em função de modelos particulares.

3. O pensamento divergente é um traço essencial da atividade científica, bem como a invenção de hipóteses e modelos ou o planejamento de experimentos. Divergências podem apresentar-se como controvérsias entre modelos.

4. A busca de coerência global conduz a contínuas revisões de resultados obtidos. Diferentes estratégias de investigação e distintas tecnologias são usadas para comprovar a precisão ou a autenticidade do conhecimento estabelecido.

5. O trabalho científico é um empreendimento histórico-social. Cada domínio de pesquisa confunde-se com uma comunidade científica. A pesquisa é regulada por meio de instituições nas quais o trabalho individual é orientado por linhas de pesquisa e interesses dos organismos de financiamento.

A ciência é uma atividade complexa que envolve esses e outros aspectos de modo que haja uma inter-relação dentre eles.

1NT Bonan traz para discussão uma das controvérsias mais longas da história da Geologia. Os modelos sobre convecção do manto são disputados desde a década de 1970 e não há prospecto do final desse debate. Independentemente das alternativas, dados e fórmulas explicativas, 0 material didático para 0 ensino básico parece alheio e continua a difundir um modelo de estado físico para as esferas internas da Terra (manto e núcleo) preso às explicações da hipótese de contração da Terra (abandonada há dezenas de anos). Na maioria dos livros didáticos do ensino básico veicula-se a ideia confusa e errônea de que o manto é pastoso e composto por magma. Isso cria dificuldades para compreender a dinâmica terrestre e principalmente as transformações relacionadas à tectônica de placas.

2NT Bonan faz uma construção epistemológica diretamente dirigida para sua análise que será exposta nos itens seguintes. É uma espécie de canibalismo epistemológico na medida em que persegue formas bastante específicas de argumentação. À primeira vista, a montagem histórica e epistemológica é muito estreita, por outro lado, a partir do exame dos dados pode-se apreender que há uma idéia dinâmica, histórica e humana de ciência. Essa noção dinâmica de ciência, cujos conceitos, processos e explicações são historicamente situados, é exemplificada por meio do modelo de estrutura interna da Terra e, no caso desta pesquisa, explicitam importante controvérsia contemporânea das Ciências da Terra. 


\subsection{Epistemologia e didática presentes na abordagem adotada}

Anguita e Sequeiros (2003) refletem sobre o potencial didático da história moderna das Ciências da Terra e atribuem especial importância aos processos geológicos internos como campo no qual houve importantes novidades recentes. Nosso propósito é desenvolver de modo esquemático a evolução de explicações sobre a convecção no manto. Pretendemos enfatizar o enfoque epistemológico da controvérsia, pois queremos acompanhar a concepção de ciência acima explicitada.

Selecionamos modelos importantes para construir o campo conceitual dos estudos sobre o manto. Os critérios utilizados assinalam três características da atividade sócio-histórica da ciência: (i) o papel divergente do pensamento científico mediante controvérsias entre modelos, (ii) a identificação de uma comunidade científica por meio de suas publicações, (iii) os avanços da tecnologia e a interpretação de dados para construir os modelos.

\subsection{Procedimentos de nossa investigação}

Recorremos a três livros de texto recentes e considerados importantes por vários especialistas que ensinam a teoria sobre convecção no manto para revelar o desenvolvimento do campo de pesquisa. A partir dessas obras, tornou-se possível identificar as distintas escolas a que pertencem seus autores e, ainda, sua intervenção ativa na história desse campo. Partindo de citações bibliográficas, foram selecionadas publicações de destaque para justificar os modelos adotados em cada escola. Incluímos, ainda, outras publicações para compor um panorama amplo do desenvolvimento do campo de pesquisa.

\section{Progresso do campo de investigaçãa $0^{3 \mathrm{NT}}$}

\subsection{Evolução conceitual do modelo}

\subsubsection{0 ponto de partida: aceitação da teoria da tectônica de placas}

A aceitação da teoria da tectônica de placas trouxe para o debate a estrutura e os processos internos da Terra. A discussão tratava sobretudo do movimento da superfície mas o mecanismo que possibilitava o mobilismo era um tema secundário. Na década de 1960, a hipótese das placas foi aceita, e implicitamente adotou-se a teoria de convecção no manto como algo que estava em acordo com os movimentos superficiais. O modelo de convecção de Hess foi muito difundido (Le Grand 1988); incorporou a expansão do assoalho oceânico e situou a convecção nos primeiros $250 \mathrm{~km}$ de profundidade. As placas subductantes representavam os ramos descendentes das células convectivas; de outro lado, as zonas dorsais eram os ramos ascendentes. O modelo de Hess pode ser considerado o consenso básico sobre o qual foram definidos os problemas a ser investigados, bem como as linhas prioritárias de pesquisa. ${ }^{4 \mathrm{NT}}$

\footnotetext{
3NT É justamente na construção do modelo de viscosidade do manto pelos autores dos livros examinados que aparece um ponto central de qualquer estudo sobre a estrutura interna da Terra. Os modelos apóiam-se em evidências da superfície do planeta. Nisso há uma boa pista para construir modelos de ensino e para refletir sobre a didática relativa à estrutura interna da Terra. Como a estrutura interna da Terra é inacessível, quer por dificuldades espaciais, quer pela dinâmica temporal dos processos, as analogias de construção de modelo apóiam-se em experimentos, observações e modelos numéricos mas é essencial assinalar que essas fontes de informação situam-se na superfície. Ora, do ponto de vista epistemológico, Potapova (1968; ver tradução em Terrae Didatica v. 3, 2007) assinalou que a crosta terrestre é uma zona de repercussão dos processos do manto. De certo modo, isso já havia sido percebido no século XIX: Charles Lyell sugere estudos sobre o campo gravitacional, momento de inércia, etc. (que podem ser observados na superfície) para construir o modelo da estrutura interna da Terra. P.ex., a construção do modelo de viscosidade do manto remete a um problema crucial de elaboração de modelos sobre fenômenos que não podem ser diretamente observados. Os dados utilizados acham-se associados a modelos numéricos, experimentos limitados devido às escalas espaciais e temporais da história da Terra e modelos indiretos sobre o comportamento dos materiais (no presente e no passado geológico). Tudo isso caracteriza modelos hipotéticos da estrutura interna do planeta por mais sofisticadas que sejam as técnicas empregadas na pesquisa. Como mencionamos acima, isso é semelhante ao que Lyell (1866), na décima edição dos Princípios da Geologia, propõe para conhecer a estrutura interna da Terra (o que modernamente denominaríamos um programa de pesquisa). Os estudos propostos partem de fenômenos observáveis na superfície como evidências do que ocorre no interior do planeta. Problemas sobre gravidade, sismicidade e calor interno da Terra buscam dirigir o estudo dos geólogos que viriam nas gerações seguintes até hoje. Os modelos construídos na atualidade acham-se marcados pelo desenvolvimento científico e tecnológico mas necessitam recorrer a dados que são construídos sobre aspectos diretamente observáveis na superfície da Terra. De certo modo, cento e cinqüenta anos depois, achamos que as indicações de Lyell perseguiam 0 caminho correto. As condições limitadas de experimentação, a impossibilidade de reconstituir o conjunto de processos que organizaram os materiais do planeta desde a formação da Terra e do Sistema Solar, o que já foi apontado por Bradley (1970), sintetizado e reforçados por Potapova (1968) e Frodeman (1995).
} 


\subsubsection{A formação de um campo de pesquisa autônomo}

A convecção do manto tornou-se um campo de pesquisa autônomo no início da década de 1960. Em 1962, surge o projeto internacional Upper Mantle Project agrupando investigadores de distintas partes do mundo. Foi organizado como um programa internacional de estudos de Geofísica, Geoquímica e Geologia para estudar o manto superior e sua influência no desenvolvimento da crosta terrestre (Knopoff 1969). Durante sua realização houve avanços em diferentes áreas geológicas. Ao concluir o projeto, as idéias mais importantes indicavam que a convecção era restrita ao manto superior, ou seja, até uma profundidade de $1.000 \mathrm{~km}$.

\subsubsection{0 surgimento de uma controvérsia}

Entre o final da década de 1970 e início da seguinte, surge um modelo de convecção global, ou seja, defende o envolvimento do conjunto dos materiais do manto, o que implica questionar a convecção confinada ao manto superior. Davies (1977) adota esse modelo como a superposição de modos diferentes e complementares: (i) modo placa, identifica as placas subductantes como fluxo convectivo que entra no manto, (ii) modo pluma, incorpora a idéia de ascenso colunar que emerge do manto profundo e atravessa até atingir a crosta terrestre.

Fisicamente esse modelo assume que placas e plumas manifestam a concentração de forças de flotação, opondo-se ao modelo de célula convectiva que era adotada pelas explicações mais antigas. Considera, ainda, que o fluxo material das dorsais é um agente passivo que não participa da convecção de grande escala.

No mesmo período, de um lado, o foco sobre a convecção é ampliado para visão planetária, de outro, as idéias da história termotectônica de evolução do planeta avançam (Schubert 1979).

\subsubsection{A propagação da controvérsia no campo de pesquisa}

A idéia de movimento do manto inferior abriu uma nova janela de possibilidades. Ritcher e McKenzie (1981) estudam a possibilidade de processo convectivo em dois sistemas separados: um situado no manto superior e outro no manto inferior. Isso ficou conhecido como modelo de conveç̧ão estratificada. A zona de transição funciona como uma barreira que separa os dois fluxos. ${ }^{5 \mathrm{NT}}$

A inclusão da convecção estratificada no debate silenciou a imobilidade do manto inferior e conduziu à aceitação definitiva de sua mobilidade.

$\mathrm{Na}$ década de 1980, dois modelos básicos (convecção global e estratificada) deram lugar ao surgimento de uma variedade de modelos que diferem entre si em aspectos parciais e excludentes. Isso conduziu ao aumento de produção científica nesse campo e, dessa maneira, um volume mais consistente de explicações.

Em 1992, Davies e Richards publicaram uma revisão mais completa do original de Davies (1977). Assinale-se uma diferença notável entre as duas versões: a quantidade de dados mencionados a favor da convecção global em detrimento dos modelos rivais, sobretudo a convecção estratificada.

Em 1993, Glatzmaier e Schubert publicam um artigo para avaliar os modelos de convecção global e estratificada como pólos opostos da convecção. $\mathrm{O}$ artigo conclui que algumas plumas emergem da zona de transição e que algumas placas não atravessam essa mesma região (não ultrapassam os 670 $\mathrm{km}$ de profundidade), isso conduz a considerar os dois modelos, convecção estratificada e zonas de convecção global. Por sua vez, no desenvolvimento termotectônico do planeta um modelo substituiria o outro durante o tempo geológico.

\subsubsection{Modelos de convecção presentes nos livros de texto}

As obras selecionadas têm como objetivo central ensinar a teoria de convecção no manto,

4NT Oreskes (2001) reconstrói os passos seguidos por Harry H. Hess (1906-1969) em sua montagem de uma explicação coerente para a deriva continental sintetizada em seu artigo de 1956 sobre a origem das bacias oceânicas. Hess reviu seu artigo de 1937 no qual apresentava correntes de convecção associadas a anomalias gravimétricas negativas das fossas oceânicas, na época imaginava que essas regiões corresponderiam a zonas de afundamento da crosta terrestre dentro do manto. Essa revisão reuniu dados paleomagnéticos, sismológicos e da topografia do fundo oceânico para associar as correntes de convecção do manto à cordilheira do Atlântico Norte. Seu modelo de correntes de convecção interpretava a crosta oceânica como a camada superior do próprio manto. Tais correntes seriam 0 motor da deriva continental e da formação do fundo oceânico.

5NT A zona de transição corresponde a uma descontinuidade sísmica que é interpretada como mudança de viscosidade entre 410 e $670 \mathrm{~km}$. 0 modelo sugere um pequeno aumento de viscosidade em $410 \mathrm{~km}$ de profundidade e um pequeno decréscimo em $670 \mathrm{~km}$. Abaixo de $670 \mathrm{~km}$ de profundidade a viscosidade deve aumentar em relação direta com a profundidade. No manto inferior, abaixo de $1000 \mathrm{~km}$ de profundidade, a viscosidade prevista deve ser duas ordens de viscosidade maior do que no manto superior (Drury e Gerald 2000). 
isso implica adotar uma atitude diante da controvérsia dos modelos. Jackson (1998) e Davies (1999) tratam da convecção global de Davies e Richards (1992) e os dois livros esquematizam o modelo convectivo global que considera ascendência de plumas, zonas de subducção e dorsais meso-oceânicas.

De outro lado, o livro publicado por Schubert, Turcotte e Olson (2001) não exibe um esquema de processo convectivo e advoga que a convecção é global, na situação geológica atual; desenvolve a convecção estratificada seguindo Glatzmaier e Schubert (1993).

Apesar das diferenças, as três obras enfatizam como foi o processo de evolução térmica durante a história da Terra, o que diminui a importância do debate atual entre convecção global versus estratificada (Bonan 2003).

\subsubsection{Como se encontra o campo de pesquisa hoje?}

A controvérsia atualmente abre um novo rumo. A discussão sobre a existência de plumas térmicas adquiriu particular relevância. Pode-se aferir esse debate em, p.ex. http://www.mantleplumes.org/. Entretanto, abordar detalhadamente o debate ultrapassa os limites deste artigo.

\subsection{Os avanços decisivos da tecnologia}

O avanço do conhecimento sobre a convecção no manto está associado fortemente ao desenvolvimento tecnológico. Novas formas de processamento informatizado de dados sísmicos foram decisivas, embora devem ser tratadas no contexto de outros elementos científicos.

O Upper Mantle Project reuniu grande parte dos estudos sísmicos que, anos depois, conduziram ao desenvolvimento da tomografia sísmica. Esta nova ferramenta tecnológica dirigiu a controvérsia para o lado da convecção global na década de 1990. Os dados obtidos revelaram que as placas nas zonas de subducção atravessam a zona de transição (670 km de profundidade) como era defendido pela convecção global.

Os modelos numéricos ou de computadores permitiram simular a convecção do manto em grande escala combinando teorias e dados de distintas origens. Em 1977, Davies recorre a eles para avaliar o confinamento convectivo no manto superior. Schubert em 1979, Ritcher e
McKenzie em 1981 e Glatzmaier e Schubert em 1993 empregam essa mesma fonte de dados. Esses modelos se, no primeiro momento, permitiram generalizar simulações bidimensionais, a medida que avançou o tratamento informatizado de dados, foram obtidas simulações tridimensionais que aperfeiçoaram a avaliação de aspectos relacionados aos processos.

\subsection{A identificação da comunidade científica}

Os autores dos livros de texto selecionados são pesquisadores ativos da comunidade científica que investiga a convecção no manto e representam institucionalmente escolas científicas diferentes. Isso é evidente pelas referências bibliográficas utilizadas neste artigo.

A obra de Jackson (1998) é uma coletânea cujos autores pertencem à Research School of Earth Science da Universidade Nacional da Austrália. A escola foi fundada no final da década de 1960 e é responsável por parte significativa da síntese geodinâmica moderna. Davies pertence a essa escola e é o autor do capítulo que desenvolve a convecção global (texto muito acessível a geólogos, geofísicos ou físicos). Uma construção mais pormenorizada e sofisticada de seu modelo é exposta em seu livro de $1999 .{ }^{\text {NT }}$

A obra de Schubert, Turcotte e Olson (2001) desenvolve a convecção desde uma perspectiva de Geologia Planetária. Seus autores pertencem a distintas universidades norte-americanas e fazem parte da American Geophysical Union. Turcotte e Schubert são, ainda, co-autores de um texto clássico de geodinâmica cuja primeira edição é de 1982. A pesquisa bibliográfica empreendida permite situar os autores como partidários históricos da convecção estratificada (Schubert et al. 2001). Esse modelo é desenvolvido no seu livro no qual apresentam os resultados obtidos por Glatzmaier e Schubert (1993).

Um exame cuidadoso da bibliografia dos livros de texto revela a formação de subgrupos de pesquisadores no interior de cada escola. Suas publicações sustentam as hipóteses afirmadas pelos modelos ensinados.

6NT Na edição de 2000 da obra editada por lan Jackson, 0 quinto capítulo é de Geoffrey F. Davies, intitulado Placas, plumas, convecção e evolução do manto (Plates, plumes, convection, and mantle evolution). 


\section{Comentários finais}

A evolução conceitual apresentada enfatiza a divergência presente no pensamento científico que se materializa em pesquisadores identificados da comunidade científica. Tal identificação permite reconstruir os caminhos no campo de pesquisa, os trabalhos feitos em colaboração por membros de uma mesma escola, os modelos que constroem ao longo do tempo e as discussões entre escolas divergentes.

Consideramos que esta forma de indagação bibliográfica é um modo de penetrar em uma reconstrução do desenvolvimento histórico de um domínio particular de investigação moderna. Admitimos que o caminho ainda é parcial e nãoexaustivo, embora permita revelar certa tipologia e incluir pesquisadores atuais em aspectos epistemológicos de relevância educativa e, sobretudo, úteis para formação de professores.

\section{Referências bibliográficas}

Adúriz-Bravo A., Izquierdo M., Estany A. 2002. Una propuesta para estructurar la formación epistemológica del profesorado de ciencias. Enseñanza de las Ciencias, 20(3):465-476.

Bonan L. 2002. Evolución del modelo de convección en el manto terrestre: Fundamentos conceptuales que estructuran su análisis didáctico. XII Simposio sobre Enseñanza de la Geología, AEPECT. Girona, julio de 2002.

Bonan L. 2003. Modelos Teóricos de Convección en el Manto. Análisis de su Evolución Disciplinar. Documento inédito elaborado en el marco de la materia: "Geofísica de la Tierra Sólida". Depto. Geología, FCEyN, UBA. Buenos Aires.

Bonan L., Sellés-Martínez J., Praia J. 2004. Las controversias como mecanismo científico a desarrollar en las clases de ciencias. Un ejemplo proveniente del estudio de la dinámica terrestre. In: Simposio sobre Enseñanza de la Geología, 13, Alicante, 2004. Actas... Alicante: AEPECT. p.48-53.

Bradley W.H. 1970. Leyes geologicas. In: Albritton Jr. C.C. ed. 1970. Filosofía de la Geología. México: Compañía Editorial Continental. p. 25-38.

Davies G. 1999. Dynamic Earth. Plates, Plumes and Mantle Convection. Cambridge: Cambridge Univ. Press. 458p.

Davies G. 1977. Whole mantle convection and plate tectonics. Geophys. J. R. Astr. Soc., 49:459-486.

Davies G., Richards M.A. 1992. Mantle convection. Journal of Geology, 100:151-206.
Drury M.R., Gerald J.D.F. 2000. Mantle rheology: insights from laboratory studies of deformation and phase transition. In: Jackson I. ed. 2000. The Earth's mantle: composition, structure, and evolution. Cambridge: Cambridge University Press. p. 503-559.

Frodeman R. 1995. Geological reasoning: Geology as an interpretive and historical science. Geological Society of America Bulletin, 107(8):960-968.

Gil D., Fernández I., Vilches A., Cachapuz A., Praia J.A., Valdés P., Salinas J. 2005. Questioning and overcoming distorted views of science: an essential requisite for the renewal of science Education. In: McComas W. ed. 2005. The nature of science in science education: rationales and strategies. Klüwer Academic Publ. 363p.

Glatzmaier G., Schubert G. 1993. Three-dimensional spherical models of layered and whole mantle convection. J. Geophys. Res. 98:21969-21976.

Jackson I. ed. 1998. The Earth's Mantle. Composition, Structure and Evolution. Cambridge: Cambridge Univ. Press. 566p.

Knopoff L. 1969. The Earth's Crust and the Upper Mantle. In: Hart, P. ed. 1969. Washington: American Geophysical Union.

Le Grand H. 1988. Drifting continents and shifting theories. Cambridge: Cambridge Univ. Press. 313p.

Lyell C. 1866. Principles of Geology. 10 ed. London: John Murray. $2 \mathrm{v}$.

Oreskes N. 2001. From continental drift to plate tectonics. In: Oreskes N. ed. 2001. Plate tectonics: an insider's history of the modern theory of the Earth. Boulder (CO): Westview Press. p. 3-27.

Potapova M.S. 1968. Geology as an historical science of nature. In: Interaction of sciences in the study of the Earth. Moscow: Progress Publisher. p.117-126. Tradução: Potapova M.S. 2008. Geologia como uma ciência histórica da natureza. Terre Didatica, 3(1):86-90. URL: http://www.ige. unicamp.br/terraedidatica/. Acesso 16.12.2008.

Ritcher F., McKenzie D. 1981. On some consequences and possible causes of layered mantle convection. Journal of Geophysical Research, 86(B7):61336142.

Schubert G. 1979. Subsolidus convection in the mantles of terrestrial planets. Annu. Rev. Earth Planet Sci., 7:289-342.

Schubert G., Turcotte D., Olson P. 2001. Mantle Convection in the Earth and Planets. Cambridge: Cambridge Univ. Press. 940p.

Sequeiros L., Anguita F. 2003. Nuevos saberes y nuevos paradigmas en Geología. Historia de las nuevas propuestas en las Ciencias de la Tierra en España entre 1978 y 2003. Llull, Sociedad Española de Historia de las Ciencias y de las Técnicas, 26:279-307. 